\title{
How do affective variables (motivation, linguistic confidence, ego-resilience) predict language-based problem-solving skills in second language learners?
}

Jeongwon Choi, Daeun Kang, Hyeeun Choi, Dongsun Yim

Department of Communication Disorders, Ewha Womans University, Seoul, Korea

Purpose: The impact of affective variables in second language acquisition is extensively researched, specifically focusing on literal language achievements, however, only a few studies have explored how these variables can predict the performance of Korean learning bilingual adults in different language domains. This study examines how affective variables (motivation, linguistic confidence, and ego-resilience) predict language-based problem-solving skills in Korean learning bilingual adults residing in Korea.

Methods: Participants were composed of 26 bilingual adults who were living in Korea during the time of data collection and were learning Korean as a second language (L2). Participants completed the survey including the Language Experience and Proficiency Questionnaire (LEAP-Q), questions on measuring affective variables (motivation, linguistic confidence, and ego-resilience), and three domains of language-based problem-solving skills (sentence comprehension, idiom comprehension, and reading comprehension).

Results: Motivation showed positive significant correlations with ego-resilience and linguistic confidence. Three significant correlations were also examined among the performance of language-based problem-solving skills: sentence comprehension and idiom comprehension, sentence comprehension and reading comprehension, and reading comprehension and idiom comprehension. Among the three affective variables investigated, linguistic confidence and ego-resilience of bilingual adults significantly predicted the performance of all three language-based problem-solving skills.

Conclusions: The linguistic confidence and ego-resilience are essential for bilingual adults to cope with the interference and stress caused by cultural and linguistic differences, which leads to an improvement of the second language learning in all three domains.

Keywords: Affective variables, Language problem-solving skills, Bilingual adults, Second language acquisition, Bilingualism

\section{INTRODUCTION}

Studies have often examined factors related to effective second language (L2) learning and how one can predict the success of language learning [1]. Among these factors, individual characteristics associated with personal or environmental variables of L2 learners are known to be important and influence learners' L2 performance [2]. The emphasis on learner-centered communicative approaches of modern language pedagogy has increased the interest in intellectual, emotional, and cognitive dimensions that compose the learner [2].

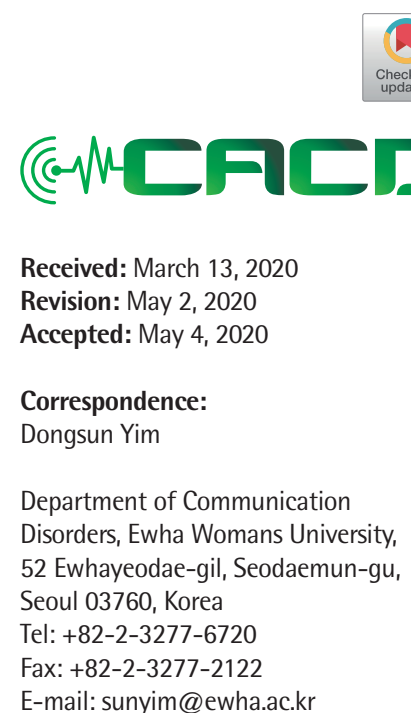

(C) 2020 The Korean Association of SpeechLanguage Pathologists

This is an Open Access article distributed under the terms of the Creative Commons Attribution NonCommercial License (https://creativecommons.org/ licenses/by-nc/4.0/) which permits unrestricted noncommercial use, distribution, and reproduction in any medium, provided the original work is properly cited. 
The majority of previous research has focused on the relationship between affective variables of English and European language learners, and their L2 performance. Throughout the self-report questionnaire, Shih [1] found that self-efficacy, L2 anxiety, and the self-regulatory strategies of 356 Thai high school students, who learned English as L2, had an impact on their academic performance. Bang and Hiver [3] investigated the relationship regarding L2 linguistic knowledge, L2 listening proficiency, strategy, anxiety, and the self-determined motivation of 300 Korean high school students who studied English as L2. These participants were evaluated on L2 vocabulary, syntactic knowledge, and listening proficiency through various test forms. They also completed the self-report survey to answer the L2 listening strategy, anxiety, and motivation items. The result indicated that intrinsic motivation, the subtype of self-determined motivation, was the most significant predictor of L2 listening proficiency. In contrast, relatively few studies have examined affective variables of people who learn less commonly taught languages (LCTL), for example, Korean as an L2. Pyun et al. [2] examined the relationship between Korean learners' affective variables (motivation, anxiety, linguistic confidence, and classroom risk-taking) and their oral achievement. The study was conducted with 104 university students in a classroom setting. Participants completed the survey questionnaire to self-measure four affective variables. Participants' oral achievement was positively correlated with linguistic confidence and risk-taking and the only significant predictor was the risk-taking variable. As their research suggested, it was important to find the relationship between affective variables and L2 learning of LCTL; the purpose of the current study is to examine if affective variables, measuring motivation, linguistic confidence, and ego-resilience, predict Korean language-based problem-solving skills in L2 learners.

Motivation is known to be the driving force that catalyzes L2 learning, maintains efforts to achieve goals [4,5], and is an important determinant of L2 acquisition [6-8]. Additionally, linguistic confidence is the primary affective variable underlying L2 acquisition, and it impacts attitudes and efforts in learning L2 [9-11]. The prior studies indicate that linguistic confidence is an important predictor of foreign language ability [10]. Egoresilience, which is related to an individual's personality, refers to a dynamic ability that produces less sensitivity to anxiety, flexibly coping with internal and external stresses, and facilitates an easy return to the previous self-control level [12, 13]. Ego-resilience controls or reduces levels of tension and endurance depending on the situation [13-15]. Thus, this study hypothesized that the degree of participants' ego-resilience would affect their ability to resolve stressors or difficulties when accepting and internalizing new information in L2 learning.

In this study, participants' language ability was measured by three different language-based problem-solving tasks. The language-based problem-solving skills measured second language learners' syntactic ability, pragmatic ability, and their overall language comprehension skill about reading in Korean. These tasks are anticipated to tap overall language domains. Cognitive flexibility is a critical component when interpreting and inferring the context to solve the idiom comprehension task. Thus, the idiom comprehension task is predicted to be significantly related to the foreign Korean learners' ego-resilience, which will be a unique variable when attempting to measure the flexibility and quality of their future language performance while handling difficulties in unfamiliar situations.

\section{LITERATURE REVIEW}

\section{Motivation}

Motivation is one of the most significant variables in determining the success of long-term L2 learning. The L2 motivational self system, which is the theoretical framework for describing learners' motivation to learn modern languages [16], has been conceptualized within various studies over the past few decades [17]. Attitudes toward L2, significant part of motivation, provides the impetus to start L2 learning [18]. In summary, motivation is the driving force that sustains a long learning process $[4,5,19,20]$. Since L2 motivation evolves with circumstances as well as cultural and psychological variables, it is complex, dynamic, and requires adaptation [20]. Additionally, as time goes on, learners can make changes in motivation, so it can be difficult to define the concept of motivation [21]. A total of 60 Persian L2 learners' self-reported responses, regarding autonomy and motivation, were studied by Hashemian and Soureshjani [22]. They concluded L2 learners with higher motivations are more successful and efficient in L2 academic performance.

\section{Linguistic confidence}

Past studies of linguistic confidence provided evidence that in learning environments accompanied by support and assistance, linguistic confidence and motivation increases [23]; learners also do not easily give up when faced with a low level 
of anxiety while using L2, which leads to L2 usage and the further development of communication skills [24,25]. Positive experiences produce greater motivation in L2 learners and allow them to develop further. Both positive and negative correlation between linguistic confidence and foreign language learning were found in much of the previous research [26-29]. Rubio [30] validated this phenomenon by asserting that the concept of linguistic confidence can be explained differently in which linguistic confidence has both psychological and social aspects, and the lower the linguistic confidence, the more likely it is to cause some psychological conditions such as anxiety, fear, or antisocial behavior that could have a negative impact on foreign language learning. However, contact with native speakers of L2 has been found to affect linguistic confidence, which leads to positive attitudes toward the L2 community and greater L2 achievement [31].

\section{Ego-resilience}

Ego-resilience is a personality trait that allows individuals to modify their way of expressing self-control for the formation and development of the self in connection to the environment [32]. Ego-resilience has a large impact on the formation of motivation [33], which, in turn, decides the direction of or goals and produces the power needed to achieve them [34]. The ability to control the level of tension and patience $[13,14]$ is more apparent in a person with high ego-resilience, and in this case, shows a general adaptation to becoming more flexible when handling difficulties in unfamiliar situations [35,36]. Luthar, Cicchetti, and Becker [15] defined ego-resilience as not just a result of successful adaptation, but rather a dynamic process that is changed and acquired in the process of development. Therefore, ego-resilience, which is the basis of learning [34], is considered a significant factor of L2 learning, which requires the ability to adapt to unique circumstances [36].

\section{Language-based problem-solving skills}

In order to examine the correlation between three affective variables: motivation, linguistic confidence, and ego-resilience, regarding language-based problem-solving skills, we investigated language-based problem-solving skills in Korean rather than just vocabulary skills. Language-based problemsolving skills are defined as the ability to, in a target language: logically think, deduce, and express in specific circumstances happening in common day to day situations [37]. Languagebased problem-solving requires metalinguistic skills that combine personal knowledge, experience, and the under- standing of contexts, circumstances, and logical relationships between events [37]. Therefore, these skills can be measured by sentences, idioms, and reading comprehension tasks. Moreover, language-based problem-solving skills that consisting of complex processes, such as interest in language, personal variables in attitudes, and contextual variables in the environment [37] are greatly influenced by affective variables such as motivation, linguistic confidence, and ego-resilience.

In this study, reading and comprehension tasks were chosen to measure language-based problem-solving skills, which require a cognitively demanding process. While reading in $\mathrm{L} 2$, it is even more cognitively demanding since it requires careful consideration of language skills, cultural backgrounds, and the learners' motivation [38]. Understanding idioms in L2 is a challenging task, but idioms are necessary for L2 learners because they are used in everyday conversations [39]. Ellis [40] stated that the knowledge of idioms and the ability to know how to use idioms in L2 are significant indicators of L2 learners' communication skills. Studies have found that even though idioms are not as arbitrary and unfamiliar as traditionally thought, their meanings can be accurately predicted by learners who know lexical elements [41].

\section{RESEARCH QUESTIONS}

This study hypothesized Korean L2 adults' affective variables (motivation, linguistic confidence, and ego-resilience) have a significant influence on their ability to solve language-based problems. In this study, the correlations and regression analyses between the language-based problem-solving skills measured through the understanding of sentences, idioms, reading, and affective variables were used to confirm which affective variables most significantly predict language-based problem-solving skills. The detailed research questions are as follows.

1. Is there a significant correlation between Korean learners' affective variables (motivation, linguistic confidence, and egoresilience) and their language-based problem-solving skills?

2. Among motivation, linguistic confidence, and ego-resilience, which affective variables most significantly predict language-based problem-solving skills?

\section{METHODS}

\section{Participants}

Participants in this study included 26 bilingual adults who 
Table 1. Means and standard deviations of participants' age, duration of learning Korean, and living duration in Korea

\begin{tabular}{llc}
\hline Variables & \multicolumn{1}{c}{ Mean } & Standard deviation \\
\hline Age & 23.76 (year) & 3.39 \\
Duration of learning Korean & 28.74 (month) & 29.28 \\
Living duration in Korea & 20.36 (month) & 16.98 \\
\hline
\end{tabular}

were residing in Korea during the time of the data collection and were learning Korean as an L2. The survey was administered to 29 bilingual adults but 3 participants with Korean as L3 and extremely low performance in language-based problem-solving tasks were excluded. Out of the 26 participants, 19 were females, and 7 were males. Participants' age ranged from 18 to 35 years old and Table 1 presents the means and standard deviations of participants' age, duration of learning Korean, and living duration in Korea. Since the nationality of the participants was not limited, foreign language learners from various countries participated in the study. Their regional origins were classified as 12 Americans (U.S. and Canada), 10 Asians (China, Japan, Taiwan, Mongol, Bangladesh, and Kyrgyzstan), and 4 Europeans (German, France, Italy, and Serbia). Their academic backgrounds consist of 6 high school graduates, 13 university graduates with a bachelor's degree, and 7 graduate or proficiency degree holders. Fourteen participants learned Korean through regular online classes, at a university language institute, or other language institutes, and eleven participants responded that they were self-taught. Two out of eleven participants who were selftaught added that they often learn Korean while talking to their Korean colleagues and that they have taken Korean classes in the past. One person responded that they learned mainly through the newspaper and had experience taking classes in the past. The participants were recruited online and offline through bulletin boards at two universities located in Seoul, referred to here as university A and university B.

\section{Instruments}

The questionnaire used in this study was made using Google Survey. It took approximately 20 minutes for participants to respond to all questions. The questionnaire consists of background information related to the use of L1, L2, affective variables (motivation, linguistic confidence, and ego-resilience), and evaluations of the participants' language-based problemsolving skills. The Language Experience and Proficiency Questionnaire (LEAP-Q) was used to obtain information on bilingual language status regarding types, frequency, and situ- ations of L1 and L2 use. LEAP-Q is a self-report and self-assessment tool for evaluating language profiles for bilingual and multilingual users [42]. LEAP-Q collects information from bilingual users in five areas: 1) language ability (including language proficiency, dominance, and preference), 2) age of language acquisition, 3) ways of language acquisition, 4) previous language exposure, and 5) current language use.

The proficiency of speaking, comprehension, and reading of the L1 (native language) and L2 or L3 (Korean) was questioned using the 5-point scale of low-fair-adequate-good-excellent to identify the level of perceived ability of their own language skills. On the questionnaire, background information about L1 and L2 use, such as duration and frequency of L1 and L2 use and the location of various environments they were used in. Also, information on how long the participant lived in countries using L1 and L2 and how often they used L1 and L2 in their workplace or school was collected regarding L1 and L2 respectively. The questionnaire also collected qualitative information about what environments the language is used in, as well as quantitative questions about how much participants are currently using their L1 and L2; in this case, L2 is Korean. The environment of language use is categorized in seven situations: interacting with friends, interacting with family, watching television, listening to music, reading, language lab/self-instruction, and listening to podcasts. Among the LEAP-Q original questions, questions regarding how foreign-language intonation has impacted participants were excluded as they were judged to be out of the scope of this study.

\section{Affective variables}

In this study, the affective variables relating to bilingual adults from various cultural and linguistic backgrounds were examined. When learning Korean in an unfamiliar environment the participants' self-assessment of their motivations, linguistic confidence, and ego-resilience were observed. Consistency of the affective variables' questionnaire was ensured with both positive and negatively phrased questions. All responses to the three affective variables questionnaire were measured on a 5-point Likert-type scale with 1 representing "strongly disagree" and 5 representing "strongly agree." The survey was designed to be written at a level appropriate to the participant's affective variables. All participants considered completed the survey in its entirety.

The eight questions on motivation were reapplied from items on the motivational scale $[6,43]$ which was used in a previous study by Pyun et al. [2]. As the previous study ques- 
tioned participants, who were learning Korean in a university class setting only, some expressions from the questionnaire were changed to apply to general situations rather than only a university class setting. The revised expressions and words are shown in parentheses. The "Korean" subject was changed to "Korean language" and "in my college program" to "in my life." The questions about motivation are as follows. The complete questionnaire is attached in the Appendix.

[Items for motivation]

-When it comes to studying Korean, I put much ( $\rightarrow$ a lot of) effort into it.

- During Korean class, I would like to have as much Korean as possible spoken (to me).

- If I had the opportunity to speak Korean outside of class $(\rightarrow$ school), I would speak Korean as much as possible.

- Korean is an important subject ( $\rightarrow$ language) to me in my college program $(\rightarrow$ life).

The eight questions on linguistic confidence were taken from the items in the Perceived Linguistic Self-Confidence statements used in the previous study [2]. This part consisted of questions that were meant to investigate the degree of linguistic confidence in learning Korean as a foreign language and using Korean in various life situations. The questionnaire is attached in an Appendix and some of the questions used in the survey are as follows:

[Items for linguistic confidence]

- I am confident I can understand most of what my teacher says in Korean class.

- I am confident I can use Korean vocabulary and expressions that I learned to interact with my teacher or friends.

- I am confident I can ask and answer various questions in Korean.

- I am confident I can talk about myself in Korean using sentences.
A total of fourteen ego-resilience questions were reapplied from the Ego-Resilience Scale [13]. Questions about participants and their ability at controlling themselves to adapt to the new circumstances were asked. The following questions were used in the survey, and the entire questions are presented in the Appendix.

[Items for ego-resilience]

- I am generous with my friends.

- I quickly get over and recover from being startled.

- I enjoy dealing with new and unusual situations.

- I regard myself as a very energetic person.

- I like to take different paths to familiar places.

\section{Language-based problem-solving skills}

The proficiency of bilingual adults who learn and use Korean for language problems solving skills were evaluated in three areas. First, Korean language expression and comprehension of sentences were evaluated in semantic areas. From questions in the Korean Oral Syntax Expression Comprehension Test (KOSECT) [44], 10 sentences were selected with accompanying photos, and two examples are shown as Figure 1 and Figure 2 . To ensure the validity of the instrument, we selected 10 questions first and then reviewed them in a pilot test. A teacher who is currently teaching Korean to foreigners at a university language institute and three foreigners who have lived in Korea for more than two years reviewed it to verify the difficulty and validity of the questions. A total of 10 questions were answered with 2.5 points for correct answers and 0 points for incorrect answers. Second, language-based problem-solving skills were examined through the evaluation of understanding idiom dependent expressions in context. The multiple-choice questions allowed the user to select the correct answer from among four options, and the difficulty of the vocabulary presented was adjusted to exclude words that
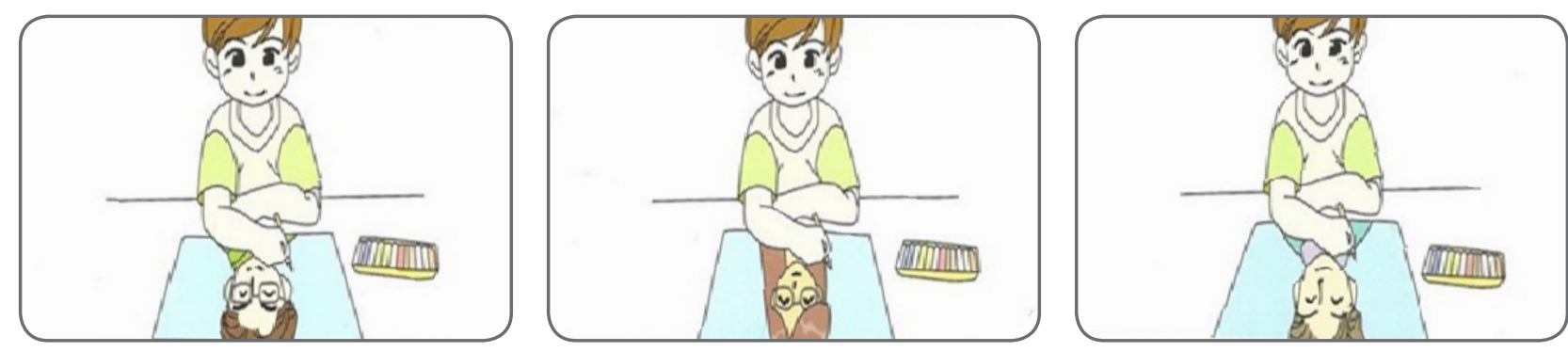

민수는 안경을 쓴 아빠를 그리고 있다.

Minsu is drawing a father with glasses.

Figure 1. Example of Korean Oral Syntax Expression Comprehension Test (KOSECT). 

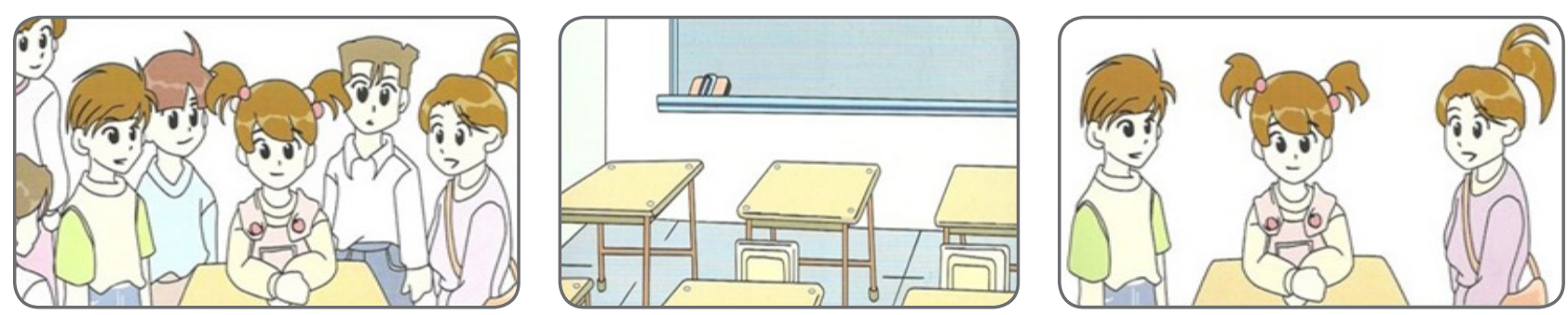

친구들이 몇명 밖에 없다.

There are only a few friends.

Figure 2. Example of Korean Oral Syntax Expression Comprehension Test (KOSECT).

were difficult to understand by Korean learners who had studied for less than two years. There were 10 questions in total, 2.5 points for the correct answer, 0 for the wrong answer, and no answer was recognized as an exception because it was a multiple-choice questionnaire. Third, reading comprehension evaluation consisted of two short texts. It consisted of 11 to 12 sentences in a text and evaluated Korean reading comprehension by asking questions about factual and inferential information regarding the text. Questions asking literal information from the text were scored as either correct or incorrect answers. Also, five questions were asking inferential information from the text, and they were graded depending on the comprehensibility of the answers with a scale of zero, one point, three points, and five points.

\section{RESULTS}

\section{Descriptive statistics}

Participants' overall responses to the measures of affective variables (motivation, linguistic confidence, and ego resilience) and performances to the language-based problemsolving tasks were analyzed using SPSS version 21.0 (SPSS Inc., Chicago, IL, USA). Table 2 presents means and the standard deviations of participants' affective variables and language-based problem-solving skills. Responses for affective variables were measured with the 5-point Likert-type scale, by participants, and the total scores were converted into percentages for a fair comparison between variables with different numbers of questions (motivation and linguistic confidence: 8, ego-resilience: 14). Each participant's total score of language-based problem-solving tasks was also converted into percentages. Among three affective variables, ego-resilience showed the highest scores $(M=54.38, S D=7.07)$, second, motivation $(M=33.72, S D=4.34)$, and third, linguistic confidence $(M=29.21, S D=8.1)$. Regarding the performance of language-
Table 2. Means and standard deviations of participants' affective variables measurement and performance of language-based problem-solving tasks

\begin{tabular}{lcc}
\hline Variables & Mean & Standard deviation \\
\hline Motivation & 33.72 & 4.34 \\
Linguistic confidence & 29.21 & 8.1 \\
Ego-resilience & 54.38 & 7.07 \\
LPST_SC & 20.52 & 5.44 \\
LPST_IC & 15.78 & 5.87 \\
LPST_RC & 25.21 & 17.19 \\
\hline
\end{tabular}

LPST, language-based problem-solving task; SC, sentence comprehension; $\mathrm{IC}$, idiom comprehension; $\mathrm{RC}$, reading comprehension.

based problem-solving tasks, participants showed the highest scores on the reading comprehension task $(M=25.21, S D=$ 17.19). They showed lower performances on the sentence comprehension $(M=20.52, S D=5.44)$, and idiom comprehension tasks $(M=15.78, S D=5.87)$.

\section{Correlation statistics}

Correlations between variables excluding several participants whose scores were too high or low. The study used SPSS version 21.0 (SPSS Inc., Chicago, IL, USA) for the statistical analysis of correlations. Pearson's product-moment correlation coefficients were used to investigate if there was a significant correlation between variables. First, significant correlations appeared between affective variables. Motivation showed a significant correlation with linguistic confidence $(r=0.499, p<$ $.01)$, and ego-resilience $(r=0.475, p<0.05)$. Second, there were significant correlations among performances of all three language-based problem-solving tasks. Sentence comprehension was significantly correlated with idiom comprehension $(r=0.594, p<0.01)$, and reading comprehension $(r=0.605, p<$ $.01)$. Idiom comprehension was significantly correlated with reading comprehension $(r=0.656, p<0.01)$. This result implies all three language-based problem-solving tasks were closely 
related. Finally, correlation analysis showed linguistic confidence had a significant correlation with sentence comprehension $(r=0.536, p<0.01)$, idiom comprehension $(r=0.393$, $p<0.05)$, and reading comprehension $(r=0.487, p<0.05)$. The correlational results are presented in Table 3 and each of the positive significant correlations is shown in Figure 3 through Figure 10.

\section{Regression statistics}

A stepwise multiple regression analysis was conducted with an

Table 3. Correlations among variables

\begin{tabular}{lccccc}
\hline Variables & $\begin{array}{c}\text { Linguistic } \\
\text { confidence resilience }\end{array}$ & $\begin{array}{c}\text { Ego- } \\
\text { SC }\end{array}$ & \multicolumn{1}{c}{ IC } & RC \\
\hline Motivation & $0.499^{* *}$ & $0.475^{*}$ & 0.041 & 0.183 & 0.180 \\
Linguistic confidence & & -0.018 & $0.536^{* *}$ & $0.393^{*}$ & $0.487^{*}$ \\
Ego-resilience & & & -0.304 & -0.282 & -0.092 \\
LPST_SC & & & $0.594^{* *}$ & $0.605^{* *}$ \\
LPST_IC & & & & $0.656^{* *}$ \\
\hline
\end{tabular}

LPST, language-based problem-solving task; SC, sentence comprehension; $\mathrm{IC}$, idiom comprehension; $\mathrm{RC}$, reading comprehension.

${ }^{*} p<0.05 ;{ }^{* *} p<0.01$.

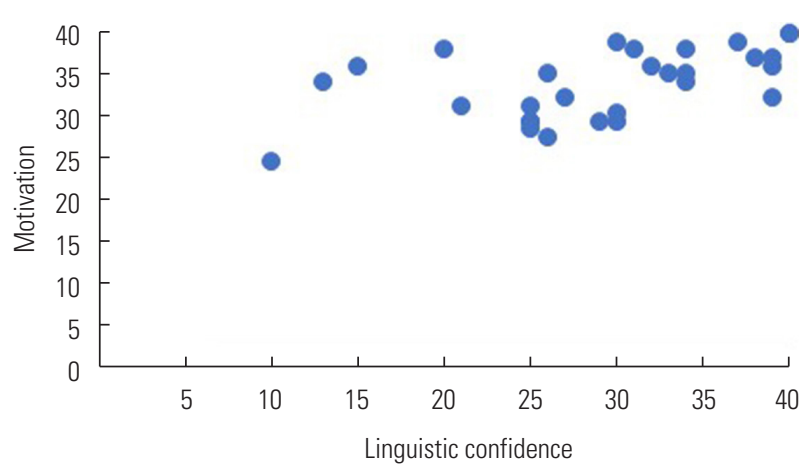

Figure 3. Correlation between Linguistic Confidence and Motivation.

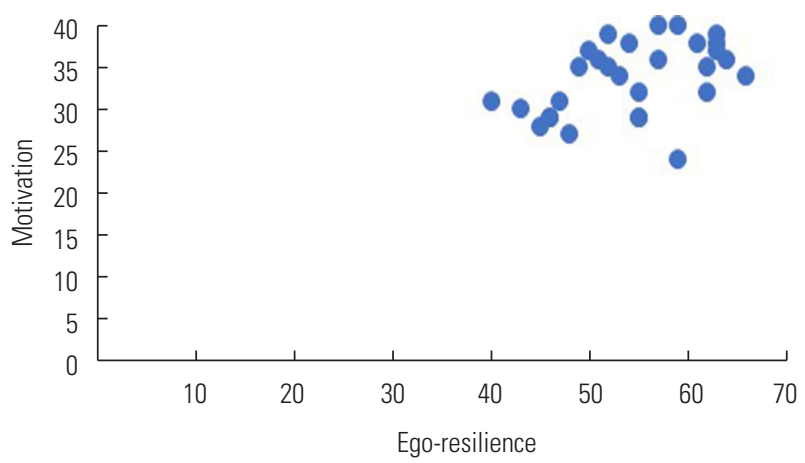

Figure 4. Correlation between Ego-resilience and Motivation.

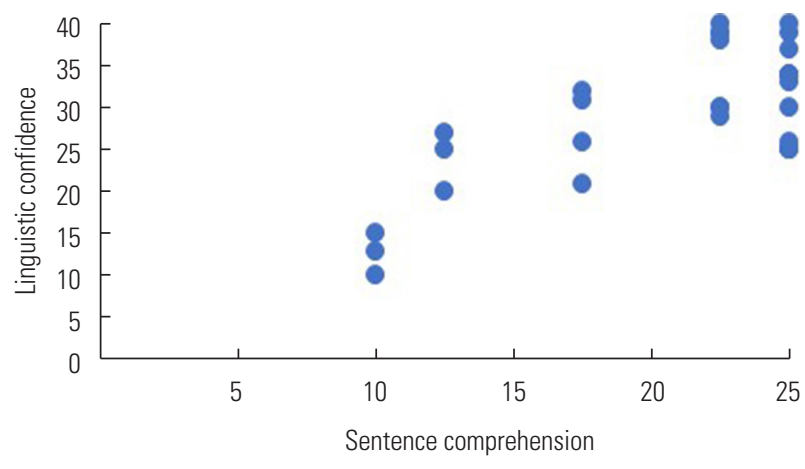

Figure 5. Correlation between LPST_SC and Linguistic Confidence.

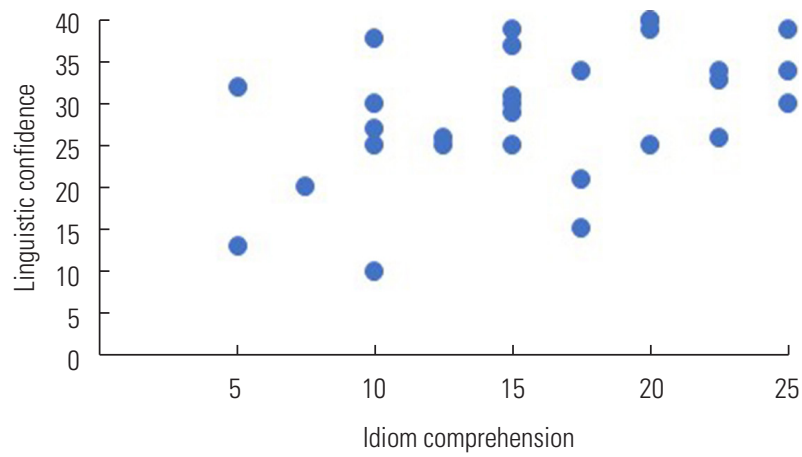

Figure 6. Correlation between LPST_IC and Linguistic Confidence.

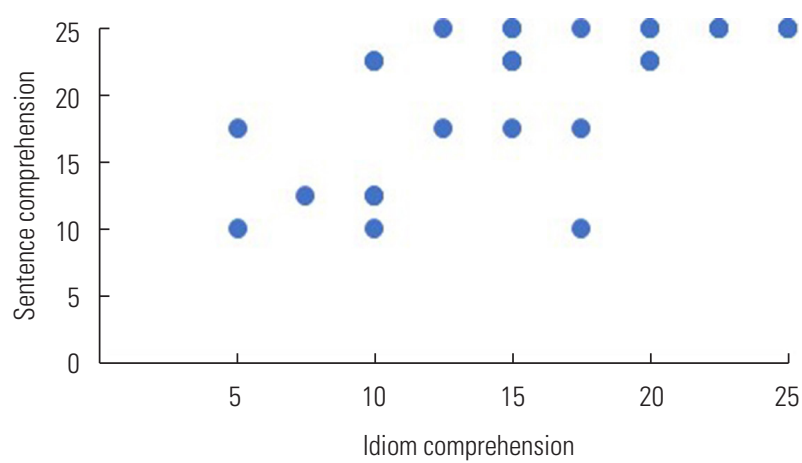

Figure 7. Correlation between LPST_IC and LPST_SC.

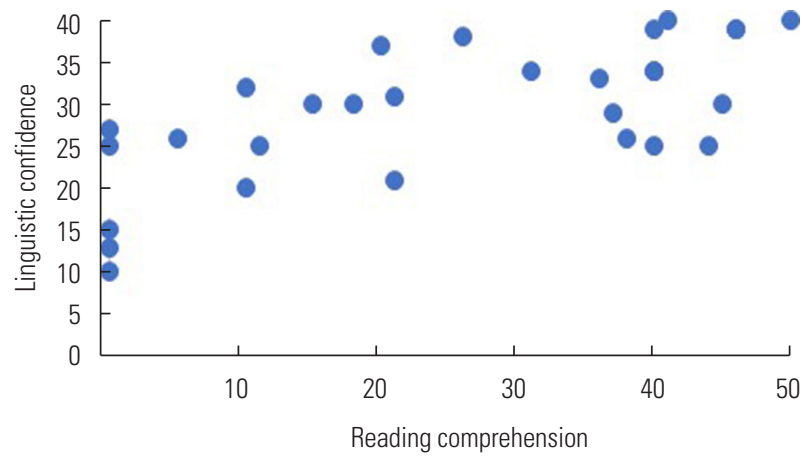

Figure 8. Correlation between LPST_RC and Linguistic Confidence. 


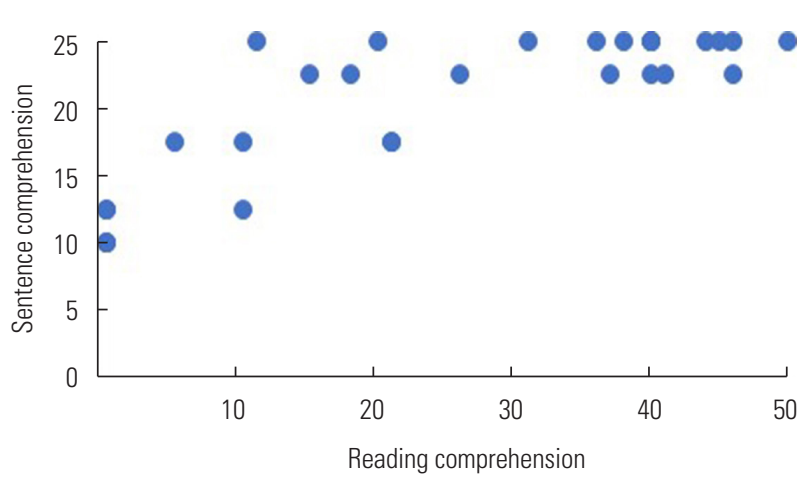

Figure 9. Correlation between LPST_RC and LPST_SC.

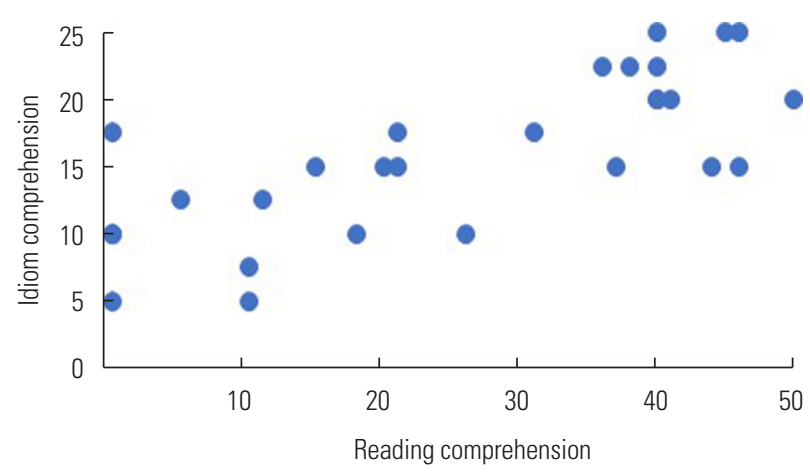

Figure 10. Correlation between LPST_RC and LPST_IC.

Table 4. Results of a stepwise multiple regression analysis

\begin{tabular}{lcccccc}
\hline & & $F$ & $R^{2}$ & Adj. $R^{2}$ & $p$ & VIF \\
\hline Ego-resilience & LPST_IC & 4.487 & 0.163 & 0.127 & $0.045^{*}$ & 1.000 \\
Linguistic confidence & LPST_IC & 6.326 & 0.365 & 0.307 & $0.007^{* *}$ & 1.022 \\
Linguistic confidence & LPST_SC & 10.900 & 0.322 & 0.292 & $0.003^{* *}$ & 1.000 \\
Ego-resilience & LPST_SC & 11.458 & 0.510 & 0.466 & $0.000^{* *}$ & 1.078 \\
Linguistic confidence & LPST_RC & 5.523 & 0.216 & 0.177 & $0.029^{*}$ & 1.000 \\
Ego-resilience & LPST_RC & 7.679 & 0.447 & 0.389 & $0.004^{* *}$ & 1.126 \\
\hline
\end{tabular}

LPST, language-based problem-solving task; SC, sentence comprehension; IC, idiom comprehension; RC, reading comprehension. ${ }^{*} p<0.05 ;{ }^{* *} p<0.01$.

independent variable being the total score of each affective variable (linguistic confidence, motivation, and ego-resilience), and a dependent variable being the total score of each language-based problem-solving task (sentence comprehension, idiom comprehension, and reading comprehension). As a result, the significant predictor of the total score of idiom comprehension was ego-resilience $\left(F_{(1,23)}=4.487, p=0.045\right)$ and linguistic confidence increased the prediction of the performance of idiom comprehension $\left(F_{(1,22)}=6.326, p=0.007\right)$. The significant predictor of the total score of sentence comprehension was linguistic confidence $\left(F_{(1,23)}=10.900, p=0.003\right)$ and ego-resilience was found as a predictor leading to a strong performance of sentence comprehension $\left(F_{(1,22)}=11.458, p=0.000\right)$. Linguistic confidence was also identified as the top significant predictor of the total score of reading comprehension $\left(F_{(1,20)}=5.523, p=0.029\right)$ and ego-resilience was found to strengthen the prediction of the performance of reading comprehension $\left(F_{(1,19)}=7.679\right.$, $p=0.004)$. The regression results are presented in Table 4 .

\section{DISCUSSION AND CONCLUSION}

In this study, motivation showed significant correlations with ego-resilience and linguistic confidence of bilingual adults learning Korean while residing in Korea. Also, three significant correlations were examined among the performance of language-based problem-solving skills: sentence comprehension and idiom comprehension, sentence comprehension and reading comprehension, and reading comprehension and idiom comprehension. Finally, linguistic confidence and egoresilience of bilingual adults significantly predicted the performance of all three language-based problem-solving skills.

As it is mentioned in the introduction, three languagebased problem-solving tasks measured different language domains. Sentence comprehension task measured syntax, reading comprehension task measured overall language comprehension as well as reading ability, and idiom comprehension task required cognitive load due to measurement of pragmatics and inferential ability. Through correlation analysis, results supported our prediction of the relationship among the language tasks. Significant positive correlations were found in all language-based problem-solving tasks, which suggest that they are systematically engaged with each other.

Although the conventional result of preceding studies reports the strong correlations between motivation and language learning, the motivation and the performance of all three language-based problem-solving skills did not show 
static correlations and it was not a significant predictor. The motivation is an important affective variable that facilitates L2 learning [18], maintains efforts to reach a goal $[4,5,19,20]$, and is a critical factor for successful learning of a foreign language [22]. However, our new result is closely connected to the preceding study and reported the motivation is a dynamic system depending on a learner's personal or environmental variables [20]. Additionally, learners can make changes in motivation while they progress, which is consistent with the argument in Lasagabaster [21] that it is difficult to accurately understand the concept of motivation because it changes individually over time. Relating this to our study, if the participants in this research did not currently study Korean when responding to the survey, and if time had passed since learning Korean, the motivation for learning Korean could have changed and their L2 motivation could have not been measured accurately. In addition, motivation without variability may have caused the result of not showing statistical correlations between motivation and language performance. Results proved that the duration of learning Korean and motivation are both correlated with linguistic confidence. Since high motivation sustains language learning $[4,5,19,20]$, which results in long time for learning Korean, linguistic confidence, and language performance would be enhanced. This indicates motivation underlies language learning and without it, participants of this study would have not even come to Korea to learn Korean. As a result, all participants' relatively high motivation could have caused almost no variability in motivation.

Results provided evidence that among the affective variables, linguistic confidence significantly predicted all three language-based problem-solving tasks. The linguistic confidence indicates communication can be promoted adaptively and efficiently when using L2 [24,25]. These results are consistent with prior studies reporting linguistic confidence as an important predictor of foreign language ability [10]. A study of international students attending the University of Toronto in Canada found international students' confidence in English is positively linked adapting to life in America [27]. Linguistic confidence is one of the most important factors in forming the motivation to learn and use a second language. Thus, linguistic confidence predicts language ability as well as adaptation to a new environment. In a multicultural environment, the dynamic between a harmonious relationship and fear determines the frequency and affinity of contact with members of an L2 group [11]. If these contacts are relatively frequent and favorable, confidence will build up with the ability to speak in a second language as well as adaptation to the new environment.

Along with linguistic confidence, the ego-resilience of the participants also predicted the performance of languagebased problem-solving tasks. Ego-resilience, resistance to stress, is a more comprehensive concept than elasticity. Egoresilience is the ability to control or reduce levels of tension and endurance depending on the situation [13-15]. Participants' personality responds positively and flexibly with egoresilience when faced with internal and external stresses or difficulties [15]. Even when a participant is dealing with the same external situation, the situation and time can change the ability to cope [13]. In this study, the period of learning Korean, and the length of living in Korea were diverse. Thus, the degree to which foreign Korean learners have adapted to the environment in Korea might have been different, and the level of tension and stress in learning Korean would have been also varied depending on the length of time spent learning Korean. Even with the possibility of differences in ego-resilience among the participants, ego-resilience strongly predicted the performance of the idiom comprehension task and increased the possibility of prediction in the sentence and reading comprehension task. Based on the research by Koh [36], cognitive skills are utilized better as ego-resilience gets higher and has features that affect adaptability and learning. The Idiom comprehension task requires cognitive load since it needs an inferential ability as well as pragmatics. It is expected that Korean language learners will also be influenced by how well they cope with the interference and stress caused by cultural and linguistic differences they experience when learning Korean as an L2 or L3 in Korea.

Socio-cultural adaptations and familiarities may vary depending on the length of residency. Thus, for future study, the effects of time changes in measuring motivation, linguistic confidence, and ego-resilience of bilingual people should be considered in exploring L2 learners. The learning circumstances for foreigners, who come to Korea specifically to study Korean, and their affective variables, are critical factors for learning a second language. Since the period of studying Korean and the length of residency in Korea may affect the performance of the tasks undertaken to measure language-based problem-solving skills, controlling factors should be considered.

The limitations of this study are as follows. First, it is hard to determine if the generalized correlation between the affective variables and language skills of bilingual adults with Korean as L2 represents the norms due to the limited number of par- 
ticipants in this survey. A future study with a higher number of participants will be more meaningful. In addition, participants' mother tongue (L1) and the academic backgrounds were not controlled. Therefore, the performance level of language-based problem-solving task difficulty in this research is likely to vary by participants.

Our suggestions for future research are as follows: future studies should consider that bilinguals' cognitive flexibility as significantly related to their second language learning. It is especially necessary to measure bilinguals' executive functions and find their implication on cognitive flexibility, which is widely known as a characteristic of bilingual speakers. Since many studies have explained bilinguals' cognitive flexibility in interfering situations between two different languages [45-47], it is worth exploring the correlation between executive functions, which represent bilinguals' cognitive flexibility, and bilinguals' second language learning and its use.

\section{FUNDING}

This research was supported by the Ministry of Education of the Republic of Korea and the National Research Foundation of Korea (NRF-2018S1A3A2075274).

\section{CONFLICT OF INTEREST}

No potential conflict of interest was reported by the authors.

\section{REFERENCES}

1. Shih H. L2 Anxiety, self-regulatory strategies, self-efficacy, intended effort and academic achievement: a structural equation modeling approach. International Education Studies. 2019;12:24-35.

2. Pyun D, Kim J, Cho H, Lee J. Impact of affective variables on Korean as a foreign language learners oral achievement. System. 2014;47:53-63.

3. Bang S, Hiver P. Investigating the structural relationships of cognitive and affective domains for L2 listening. Asian-Pacific Journal of Second and Foreign Language Education. 2016;1:1-19.

4. Dörnyei Z. The psychology of the language learner: individual differences in second language acquisition. Lawrence Erlbaum Associates Publishers; 2005.

5. Zimmerman B, Schunk D. Motivation: an essential dimension of self-regulated learning. In: Zimmerman B, Schunk D, editors. Motivation and self-regulated learning. New York: Lawrence Erlbaum Associates; 2008. p. 3-11.

6. Gardner R. Social psychology and second language learning: The role of attitudes and motivation. London: Edward Arnold; 1985.
7. Gardner R. Integrative motivation and second language acquisition. Motivation and Second Language Acquisition. 2001;23:1-19.

8. Gardner R. Motivation and second language acquisition: the socio-educational model. New York: Peter Lang; 2010.

9. Clément R. Second language proficiency and acculturation: an investigation of the effects of language status and individual characteristics. Journal of Language and Social Psychology. 1986; 5:271-290.

10. Clément R, Dörnyei Z, Noels K. Motivation, self-confidence, and group cohesion in the foreign language classroom. Language Learning. 1994;44:417-448.

11. Clément R, Kruidenier B. Aptitude, attitude and motivation in second language proficiency: a test of Clément's Model. Journal of Language and Social Psychology. 1985;4:21-37.

12. Block JH, Block J. The role of ego-control and ego-resiliency in the organization of behavior. The Minnesota Symposium on Child Psychology. 1980;13:39-101.

13. Block J, Kremen A. IQ and ego-resiliency: conceptual and empirical connections and separateness. Journal of Personality and Social Psychology. 1996;70:349-361.

14. Kim Y, Lee S, Baik J. Cognitive correlates of complexity, accuracy, and fluency in L2 spoken and written production. Applied Linguistics. 2014;30:89-113.

15. Luthar SS, Cicchetti D, Becker B. The construct of resilience: a critical evaluation and guidelines for future work. Child Development. 2000;71:543-62.

16. Lamb M. A Self system perspective on young adolescents' motivation to learn English in urban and rural settings. Language Learning. 2012;62:997-1023.

17. Dörnyei Z, Ryan S. The psychology of the language learner revisited. New York: Routledge Taylor \& Francis Group; 2015.

18. Deci E, Koestner R, Ryan R. Extrinsic rewards and intrinsic motivation in education: reconsidered once again. Review of Educational Research. 2001;71:1-27.

19. Oroujlou N, Vahedi M. Motivation, attitude, and language learning. Procedia-Social and Behavioral Sciences. 2011;29:994-1000.

20. Dörnyei Z, Ushioda E. Motivation, language identity and the L2 self. Bristol: multilingual Matters; 2009.

21. Lasagabaster D. English achievement and student motivation in CLIL and EFL settings. Innovation in Language Learning and Teaching. 2011;5:3-18.

22. Hashemian M, Soureshjani K. The Interrelationship of autonomy, motivation, and academic performance of persian L2 learners in distance education contexts. Theory and Practice in Language Studies. 2011;1:319-326.

23. Ushioda E. Motivation as a socially mediated process. In: Little D, Ridley J, Ushioda E, editors. Learner autonomy in the foreign language classroom: teacher, learner, curriculum and assessment. Dublin: Authentik; 2003.

24. Noels K, Pon G, Clément R. Language, identity, and adjustment: the role of linguistic self-confidence in the acculturation process. Journal of Language and Social Psychology. 1996;15:246-264.

25. Clément R, Bourhis R. Bilingualism and intergroup communica- 
tion. International Journal of Psycholinguistics. 1996;12:171-191.

26. Klein J, Keller J. Influence of student ability, locus of control, and type of instructional control on performance and confidence. The Journal of Educational Research. 1990;83:140-146.

27. Pak A, Dion K, Dion K. Correlates of self-confidence with English among Chinese students in Toronto. Canadian Journal of Behavioural Science/Revue Canadienne Des Sciences Du Comportement. 1985;17:369-378.

28. Lawrence D. Enhancing self-esteem in the classroom. London: Paul Chapman Publishing; 2006.

29. Roy F, Baumeister JD, Campbell JI, Krueger I, Kathleen DV. Doeshigh self-esteem cause better performance, interpersonal succes, happinessor healthier lifestyle? Psychological Science in the Public Interest. 2003;4:1-44.

30. Rubio F. Self-esteem and foreign language learning. Newcastle: Cambridge Scholars Publishing; 2007.

31. Cheng H, Dörnyei Z. The Use of Motivational Strategies in Language Instruction: the case of EFL teaching in Taiwan. Innovation in Language Learning and Teaching. 2007;1:153-174.

32. Klohnen E. Conceptual analysis and measurement of the construct of ego-resiliency. Journal of Personality and Social Psychology. 1996;70:1067-1079.

33. Rouse K. Resilient students' goals and motivation. Journal of Adolescence. 2001;24:461-472.

34. Park Y, Hyun E. Ego-resilience and stress coping styles of adolescents. Journal of Korean Home Management Association. 2007;25: 83-94.

35. Park H. Perceived stress, coping process and depression to egoresilience (Masters dissertation). Seoul: Korea University; 1996.

36. Koh M. Relations of ego-resiliency, decision making style, and attributional style: with attachment and life stress (Masters disserta- tion). Seoul: Sungshin Women's University; 2002.

37. Shin $\mathrm{H}$. A study of the correlation between idiom comprehension and verbal problem solving abilities. Journal of Speech-Language \& Hearing Disorders. 2015;24:39-49.

38. Sellers V. Anxiety and reading comprehension in Spanish as a foreign language. Foreign Language Annals. 2000;33:512-520.

39. Cooper T. Processing of idioms by L2 learners of English. TESOL Quarterly. 1999;33:233-262.

40. Ellis R. Second language acquisition. Oxford: Oxford University Press; 1997.

41. Akbarian I. Book review: measuring second language vocabulary acquisition. Language Testing. 2012;29:597-601.

42. Marian V, Blumenfeld H, Kaushanskaya M. The language experience and proficiency questionnaire (LEAP-Q): assessing language profiles in bilinguals and multilinguals. Journal of Speech, Language, and Hearing Research. 2007;50:940-967.

43. Gardner R, Tremblay P, Masgoret A. Towards a full model of second language learning: an empirical investigation. The Modern Language Journal. 1997;81:344-362.

44. Pae S, Lim S, Lee J, Jang H. Korean Oral Syntax Expression Comprehension Test (KOSECT). Seoul: Seoul Community Rehabilitation Center; 2004.

45. Festman J, Rodriguez-Fornells A, Münte T. Individual differences in control of language interference in late bilinguals are mainly related to general executive abilities. Behavioral and Brain Functions. 2010;6:1-12.

46. Weiss D, Gerfen C, Mitchel A. Speech segmentation in a simulated bilingual environment: a challenge for statistical learning? Language Learning and Development. 2009;5:30-49.

47. Kovács Á, Mehler J. Flexible learning of multiple speech structures in bilingual infants. Science. 2009;325(5940):611-612. 